\title{
Intra Project Team Disagreement, Conflict Communications, and Team Performance in Cross-Functional New Product Project Teams: A Decision-making Quality Perspective
}

\author{
Tsun-Jin Chang \\ Department of Marketing Management, Shih Chien University \\ Shang-Pao Yeh \\ Department of Tourism, I-Shou University
}

Accepted: October 2013

\begin{abstract}
This paper develops and examines a model of the antecedents and consequences of decision-making comprehensiveness during the new product development process. This model suggests first a concave relationship between intrateam task disagreement and decision-making comprehensiveness. It also conjectures that conflict communications influence the effectiveness of decision-making comprehensiveness on new product project teams' performance. An empirical test of the proposed framework involves a survey of 220 cross-functional new product project teams. The findings show that an inverse U-shaped relationship exists between a project's intrateam task disagreement and its decision-making comprehensiveness. It also indicates that collaborative communication has a negative effect on innovativeness, whereas contentious communication adversely affects constraint adherence. However, decision-making comprehensiveness partially moderates the relationships between conflict communications and project team performance. Some managerial and research implications of the findings were also discussed in this study.
\end{abstract}

Key words: conflict communications, project team performance, decision-making

JEL: M100, O130, 320, 330

1

\section{Introduction}

Cross-functional new product project teams are thought to facilitate the integration of the divergent perspectives and different information resources required in the innovation process. Firms therefore increasingly rely on mechanisms consisting of members from $\mathrm{R} \& \mathrm{D}$, marketing, manufacturing and sales as an effective way of developing successful new products (Sethi, 2000; Lovelace, Shapiro \& Weingart, 2001; Lu $\&$ Chang, 2002). But project team functional diversity does not always have positive effects on performance. The overall effect of diversity on team performance might be negative, especially in times of crisis or rapid change, because the advantages provided by multiple perspectives are often offset by problems in generating consensus (Brown \& Eisenhardt, 1995). Dougherty (1992) found that functional diversity resulted in cross-functional new product project team members with widely varying perspectives on strategies for achieving product innovation. When a project team was unable to recognize and reconcile these different perspectives, the development of successful innovative products is not feasible.

The above discussion suggests that intrateam task disagreement and decision-making comprehensiveness are concepts at the very core of using cross-functional new product project teams. Intrateam task disagreement describes the extent to which the differences among team members' perceptions and positions of the project's strategies, goal priorities and overall objectives (Song, Xie \& Dyer 2000). Decisionmaking comprehensiveness describes the extent 
to which the team is exhaustive as it considers multiple approaches, courses of action and decision criteria in its strategic decisionmaking (Slotegraaf \& Atuahene-Gima, 2011; Mitchell, Nicholas \& Boyle, 2009).

Empirical research indicates that disharmony among functions in cross-functional new product project teams is the rule rather than the exception (Griffin \& Hauser, 1996). Normally, team integration is difficult to achieve in crossfunctional settings, because people from different functional areas hold biases towards and stereotypes of one another. These biases and stereotypes arise largely from deeplyrooted functional identities that people hold (Sethi, Smith \& Park, 2001). At the same time, in an increasingly dynamic environment, firms and cross-functional project teams are being forced to become more consensual to effectively find integrative and innovative solutions. Brown and Eisenhardt (1995) suggested that the NPD process as a disciplined, problem-solving process involving many decision-making activities was geared towards finding solutions to critical customer problems.

This dilemma raises the research questions that are at the heart of this study: What is the relationship between intrateam task disagreement and decision-making comprehensiveness? How does a project team's decision-making comprehensiveness affect its performance? Do different conflict communications have different moderating effects on their relationship to project team performance? In this study, a theoretical model aiming to discuss the relationship among intrateam task disagreement, decision-making comprehensiveness and project team performance was proposed.

Overall, a major objective of this study was to develop and test a theoretical model that addresses the link between intrateam task disagreement and project team performance, including the mediating role of decision-making comprehensiveness and the moderating effect of conflict communications. We then examined the proposed framework using data from a survey of 220 cross-functional new product project teams.

Our empirical evidence indicates a concave relationship between intrateam task disagreement and decision-making comprehensiveness. We found a negative effect of collaborative communi- cation on innovativeness and a negative effect of contentious communication on constraint adherence. The results also show two significant interaction effects. Collaborative communication improves the effect of decision-making comprehensiveness on innovativeness on the one hand, whereas contentious communication seems to lessen the negative effect of decision-making comprehensiveness on constraint adherence on the other. Undoubtedly, these findings provide some important research and practical implications.

\section{2}

\section{Theoretical framework}

To explore the three research questions noted previously, we begin developing several research hypotheses which link the following variables: intrateam task disagreement, decision-making comprehensiveness, conflict communications and project team performance. We then present our theoretical framework at the end of this section, which links the specific hypotheses on which the research questions focus.

\subsection{Intrateam task disagreement and decision-making comprehensiveness}

The literature presents contradictory evidence in terms of the relationship between intrateam task disagreement and decision-making comprehensiveness. Rather than weighing in on one or another side of the debate, this study would like to propose a reconciliation of these perspectives. In short, it was suggested that the relationship between intrateam task disagreement and decisionmaking comprehensiveness is curvilinear or inverse U-shaped.

Positive effects occur for the following reasons. Higher decision-making comprehensiveness reflects a more exhaustive decisionmaking approach, involving consideration and analysis of a wide array of information and many courses of action (Fredrickson \& Mitchell, 1984). Because NPD activities are non-routine and involve considerable uncertainty and a higher level of task variability (Xie, Song \& Stringfellow, 1998), intrateam task disagreement may enhance a team's decision-making comprehensiveness by mirroring the complexity of the competitive environment. As a result, a greater quantity of information and ideas is generated (Brown \& Eisenhardt, 1995). Furthermore, 
disagreement encourages information mobilization and provides a strong incentive for various functions whereby a team can gather and share relevant information in the face of conflicting ideologies. An increased information flow decreases uncertainties in product design, testing and launching. The reduction in these uncertainties improves new product performance (Xie, Song \& Stringfellow, 1998). Finally, intrateam task disagreement can encourage a more thorough evaluation of alternatives, which increases the chance of developing high-quality decisionmaking. For example, as Brown and Eisenhardt (1995) suggested, disagreement can prevent tunnel vision and inflexibility in problem-solving process.

Negative effects of intrateam task disagreement can occur for three reasons. First, from the perspective of resource-management, extensive disagreement is not only costly to manage and apply to resolving conflicts around a team, but the team will also be unlikely to obtain the resources needed for new product development. The resultant waste and lack of resources is likely to hamper the quality of the team's decision-making process. Second, intrateam task disagreement hinders a team from achieving consensus. Dougherty (1992) found that, when the team's disagreements became extensive, their members became more committed to their individual positions and consensus became more difficult to achieve. Positional commitments and lack of consensus interfere with the group's ability to find integrative, innovative solutions. Such disagreement reflects the absence of superordinate goals and the presence of local, rather than global interpretive schemes or values (Xie, Song \& Stringfellow, 1998). Each functional area may focus on optimizing the product aspects that relate to its own function, while the decision may neglect crucial and vital information and result in lower quality of new product decisions. Third, disagreement may be detrimental to the harmony of crossfunctional relationships. Rationally speaking, intrateam task disagreement is considered merely an aspect of task conflict, but a connection unavoidably exists between task and emotion. Bourgeois and Eisenhardt (1988) have therefore suggested that constructive criticisms during debate may be misconstrued as attempts to gain unfair personal or functional advantage or as a challenge to the skills and competence of the team members whose views are being criticized.

The above discussion suggests an inverse U-shaped relationship between intrateam task disagreement and decision-making comprehensiveness. According to the concept of diminishing returns, it appears that the increase in the positive effect of decision-making comprehensiveness is less when intrateam task disagreement increases. Yet, beyond a moderate level of intrateam task disagreement, the increase in the negative effect of decision-making comprehensiveness can be more significant. Accordingly, an inverted $U$ curve reflects both the beneficial and the harmful effects of intrateam task disagreement on decision-making comprehensiveness. Thus, this study predicts:

Hypothesis 1: The relationship between intrateam task disagreement and decisionmaking comprehensiveness is inverse $U$ shaped.

\subsection{The effect of decision-making comprehensiveness}

As for the perspective of disciplined problem solving, NPD can be described as a disciplined, problem-solving process that involves many decision-making activities geared towards finding solutions to critical customer problems (Brown $\&$ Eisenhardt, 1995). When the team members are encouraged to exhaustively consider multiple approaches, courses of action and decision criteria in their strategic decision-making, managers increase the team members' ownership of the NPD process. This ownership motivates people with different backgrounds and responsibilities to confront conflicts rather than passively avoiding them and to collaborate with others for overall success rather than pursuing their own functional objectives (Dyer \& Song 1997; Song, Xie \& Dyer 2000).

Moreover, decision-making comprehensiveness enhances strategic coordination and commitment in the NPD process. As Miller (2008) suggested, when the decision-making approach becomes more exhaustive, it reduces the potential for the project team to fall victim to the specific cognitive biases associated with incomplete information. This enables decision-makers to become more realistic and effective in their assessment of the environment. Additionally, a higher level of comprehensiveness reflects a greater investment of time and energy in the 
decision process, which can elevate commitment to finding and implementing a superior solution (Miller, 2008).

Finally, empirical evidence shows that comprehensiveness in the decision-making process is of direct value for new product advantage (Slotegraaf \& Atuahene-Gima, 2011; De Luca \& Atuahene-Gima, 2007). That is, higher levels of comprehensiveness can be more beneficial for generating a superior new product innovation. Therefore, we predict that

Hypothesis 2: The level of decision-making comprehensiveness is positively related to a cross-functional new product project team's performance.

\subsection{The effects of collaborative and contentious communication}

Collaborative communication. Dougherty (1992) observed that intrateam disagreements helped functional representatives recognize their different interpretations and the need to incorporate these differences into the product their team was designing. However, unless collective action or efforts were used to create shared understandings from disparate perspectives, the functional thought world boundaries may dominate.

Firstly, when team members communicate intrateam task disagreement collaboratively, attempts are made to "enlarge the pie" rather than on merely agreeing on how to divide it (Song, Xie \& Dyer, 2000). Thus collaborative communication improves the quality of crossfunctional information, facilitates cross-functional involvement, and increases cross-functional harmony, building a surrounding that has significant positive effects on a team's longterm innovation performance. Additionally, because collaborative communication combines high assertiveness with high concern for others, participants work cooperatively towards a winwin solution by bringing all the relevant issues into the open, sharing information, and analyzing the situation objectively (Xie, Song \& Stringfellow, 1998:196). In such a collaborative context, team members tend to understand the other functions' needs, concerns and perspectives, and successfully communicate their own. Thus collaborative communication is helpful to them in adhering to budget and schedule constraints.
Consistent with the above argument, Dougherty (1992:179) concluded that collaboration (i.e. collaborative mechanisms) is necessary to technology-market linking, which means that collaboration enhances the product's design along with improving the execution of the development process. Therefore, we predict that

Hypothesis 3: The level of collaborative communication is positively related to a crossfunctional new product project team 's performance.

Contentious communication. Conversely, the message typically associated with contentious, or win-lose communications is generally more pessimistic (for example, "We cannot satisfy everyone's interests", or "You win some, you lose some") (Lovelace, Shapiro \& Weingart, 2001:781)

Contentious communication can affect team performance in two ways. First, contentious communication may make consensus so costly in time and resources that team members may try to avoid conflict altogether. That is, they may choose to ignore conflict rather than to confront it. However, avoiding cross-functional disagreements or conflicts can be very harmful to team performance, specifically when it comes to innovation. After all, integrating diverse perspectives of all functions is necessary to mirror the complexity of the competitive environment (Xie, Song \& Stringfellow, 1998). Second, contentious communication is more self-interested and punitive, thereby adversely forcing the team to consider multiple approaches, courses of action and decision criteria in its strategic decision-making. Without a thorough evaluation of alternatives and debate about critical issues between technical experts and marketers in the new product selection and design stages, the result is likely to be a product with technological excellence but little consumer appeal (Xie, Song \& Stringfellow, 1998:196).

Because contentious communication both decreases the incentive to resolve cross-functional conflicts collectively and cooperatively, and imposes one's way or position by force, this study expects it to be negatively related to both innovativeness and constraint adherence in a cross-functional new product project team. 
Therefore, we predict that:

Hypothesis 4: The level of contentious communication is negatively related to a cross-functional new product project team's performance.

\subsection{The interaction between decision- making comprehensiveness and collaborative/contentious communication}

In addition to the main effects of decisionmaking comprehensiveness and collaborative/ contentious communication on project team performance, this study also conjectures that there is an interaction between these two variables. For three reasons, this study expects that a high level of collaborative communication strengthens the positive effect of decisionmaking comprehensiveness on team performance, whereas a high level of contentious communication weakens the positive effect of decisionmaking comprehensiveness.

First, in terms of time- and resourcesconsuming, reaching a consensus can be more expensive in teams whose members communicate contentiously than in teams which communicate collaboratively. This is because implementing an integrative method can be very costly when high levels of interfunctional conflict make it more difficult to achieve resolution (e.g., a win-lose communication manner) (Lawrence \& Lorsch, 1967). Integrative strategies are effective only in situations involving a low conflict of interest and negotiable issues (e.g., a win-win communication manner) (Phillips \& Cheston, 1979).

Second, in terms of the quality of decisionmaking, collaboration is more likely to lead to sound decisions on new product selection, design and launch, because it facilitates integration of diverse skills, resources and perspectives, resulting in the most jointly optimal solutions (Xie, Song \& Stringfellow, 1998).

Third, to discover novel linkages among ideas and concepts to reach decision-making comprehensiveness, team members require surfacing and challenging assumptions held by various team members (Mason \& Mitroff 1981). Under such conditions, it requires at least that team members feel free to express opinions, perspectives and beliefs that differ from those held by others in the team. In comparison with contentious communications, collaborative communications are more helpful to decision-making comprehensiveness. Indeed, collaborative communications have qualities that have been identified with brainstorming communications (Innami 1994). Therefore, we predict that

Hypothesis 5: There is a positive interaction effect between decision-making comprehensiveness and collaborative communication on a cross-functional new product project team's performance.

Conversely, we predict that:

Hypothesis 6: There is a negative interaction effect between decision-making comprehensiveness and contentious communication on a cross-functional new product project team's performance.

\subsection{The conceptual framework}

A conceptual model to link the hypothesized relationships among the specific variables on which this study focuses is depicted in Figure 1. This model includes four components. The first discusses the relationship between intrateam task disagreement and decision-making comprehensiveness. The second describes the effect of decision-making comprehensiveness on project team performance. The third component shows the effects of these two conflicts communication, that is, collaborative and contentious communications, on project team performance. Finally, the moderating effects of two conflict communications on the relationship between decision-making comprehensiveness and project team performance were introduced into our conceptual model. In terms of measuring team performance, drawing upon the viewpoints of Lovelace, Shapiro and Weingart (2001), innovativeness and constraint adherence were applied in this study. 


\section{Figure 1}

A model of antecedents and consequences of comprehensive decision-making in cross-functional new product project teams

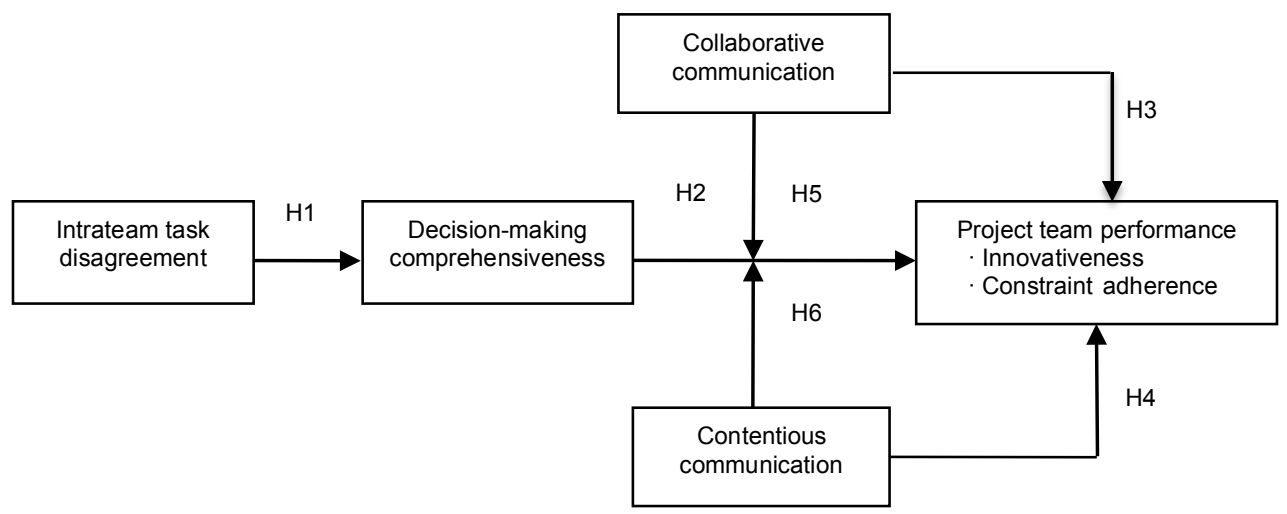

3

Methods

\subsection{Data collection}

Following a similar key informant research procedure (Sethi, 2000), this paper tested the hypotheses using data collected by means of a mail survey of key informants in crossfunctional teams involved in recent major new product initiatives. The aim is to identify and contact people who would be highly knowledgeable about team events and practices. In this study, such persons were team/project members, regardless of their assigned functions. To obtain access to new product teams or projects, this study identified high-tech firms in the telecommunications and semiconductor industries around Kaohsiung, Taiwan. Then this study contacted the team leader, with the permission of their firms and their personal agreement, with a letter requesting their participation, listing the criteria for team selection, and assuring them of company anonymity. If a firm and their team leaders agreed to participate in this study, a confirmation letter was sent to a company contact.

The mail survey procedure suggested by Dillman (1978) was primarily followed in this study. Additionally, the data collection method adopted by Slotegraaf and Atuahene-Gima's study (2011) was applied here. From each team (several teams were allowed from a firm), data was collected from two key informants who has been involved in the same recent NPD project. We asked the project leader to select the most recent new product launched within the last three years. The project leader (or the internal team leader, as suggested by Lovelace, Shapiro \& Weingart, 2001) provided information on innovativeness and constraint adherence. A second respondent, nominated by the team leader as being knowledgeable about and involved with the project selected, provided data in terms of intrateam task disagreement, decision-making comprehensiveness, team-level debate, and the control variables. Two respondents from each team were also asked to provide information about the relevant variables, individuals' functional background, and demographic characteristics.

To confirm that the sample size we received was adequate, a confidence interval approach was employed to estimate the needed sample size. ${ }^{1}$ Given that we collected empirical data through a seven-point Likert-type scale questionnaire, and the desired sample size was determined by using a 95 per cent confidence interval and a margin of error of $0.35(7 * 5$ per cent $=0.35)$, the maximum possible population variation in this questionnaire is 9. Accordingly, we can get a desired sample size of 283 . $^{3}$ Actually, 220 pairs of usable responses were in the final sample.

\subsection{Measures}

Whenever possible, existing measures of the constructs were used. All measures were pretested on several MBA program students in 
I-Shou University, Taiwan. Following the pretest, a panel discussion on questionnaire items was held with several managers to ascertain their interpretation of the items in the measures. On the basis of information feedback, the questionnaire was further revised and administered to the full sample. Descriptive statistics and reliability for each measure and correlations among measures are shown in Table 1.

\subsubsection{Project team performance}

Drawing upon the perspectives of Sethi, Smith, and Park (2001) and of Lovelace, Shapiro, and Weingart (2001), this study conceptualized team performance as two conceptually-related components: innovativeness and constraint adherence. New product innovativeness was operationalized as the extent to which a new product is perceived to be novel in comparison with other competing products. This measure is a slight modification of the creativity scale suggested by Andrews and Smith (1996). The innovativeness scale is a seven-item, sevenpoint semantic differential scale that taps the novelty dimension of innovativeness. The constraint adherence measure included the team's progress compared with the managers' initial expectations, its cost performance, its adherence to schedules and budgets (Lovelace, Shapiro \& Weingart 2001). A new four-item, seven-point Likert-type scale was developed to measure constraint adherence.

\subsubsection{Intrateam task disagreement}

Intrateam task disagreement was operationalized as the extent to which the decision-making among team members involved disagreement, challenge, and dissent regarding the project's strategies, objectives and goal priorities. The intrateam task disagreement measure is based on a measure proposed by Simons, Pelled and Smith (1999). The intrateam task disagreement scale is a three-item, seven-point Likert-type scale.

\subsubsection{Decision-making comprehensiveness}

Decision-making comprehensiveness was measured as the degree to which decision-making in the NPD project involved consideration of a large number of alternatives, multiple criteria for evaluating the alternatives and extensive examination of opportunities and possible courses of action. A four-item scale from
Miller, Burke and Glick (1998) was adapted to measure decision-making comprehensiveness.

\subsubsection{Collaborative/Contentious communication}

This measure was based on a measure applied by Lovelace, Shapiro and Weingart (2001), representing the degree of team members' perception of information-sharing, importance of the working relationship, fixed-sum perceptions and personal attacks. A 17-item, seven-point Likert-type perception statement was adapted to measure collaborative (11-item) or contentious (6-item) communication.

\subsection{Controls}

In order to reasonably assess relationships among variables, this study will include other variables known or expected to affect those relationships proposed in this study as controls. This study hypothesizes five variables that represent team- or organization-specific controls, which were then included in the decisionmaking comprehensiveness model and project team performance model respectively.

\subsubsection{Team-specific controls}

The first control, leader effectiveness, was measured on a six-item, seven-point Likerttype scale. The measurement included the items in the innovation group leadership measure used by Van de Ven and Chu (1989). The second control, freedom to express doubts, was measured on a three-item, seven-point Likert-type scale that captured the degree of freedom to express the team members' doubts about the direction being taken, matters occurring in the team, and the feasibility of what was being conducted.

\subsubsection{Organization-specific controls}

The first control, external environmental forces, was measured on a two-item, sevenpoint Likert-type scale to measure the external environment. One item was for the degree of competition, and the other for the degree of technological dynamism in the environment. This measure was based on one used by Nohria and Gulati (1996). The second and third controls represent two conceptuallyrelated variables of organizational internal control: formalization and centralization. Of the structural dimensions in an organization, 
the two most prominent internal controls affecting innovativeness are formalization and centralization (Lu \& Chang, 2002; Nohria \& Gulati, 1996). Formalization measured the extent to which employee behavior was subject to formal controls, such as job descriptions, rules, procedures and formal written documents. An additive scale of five-item, seven-point indicators was used to measure the degree of formal control over employee behavior based on the suggestions by Lu and Chang (2002). Centralization indicated the degree to which authority to make key decision areas was kept at the top level of the organization. We used an additive scale of five seven-point items as a measure to assess the degree of key decisions that were centralized, based on suggestions by Nohria and Gulati (1996) and Lu and Chang (2002).

Table 1

Correlations among primary measures

\begin{tabular}{|ll|c|c|c|c|c|c|c|c|}
\hline \multicolumn{1}{|c|}{ Variables } & Mean & S.D. & $\mathbf{1}$ & $\mathbf{2}$ & $\mathbf{3}$ & $\mathbf{4}$ & $\mathbf{5}$ & $\mathbf{6}$ \\
\hline 1 & 4.16 & .60 & 1.00 & & & & & \\
\hline 2 & Innovativeness & 5.02 & .66 & $.26^{* *}$ & 1.00 & & & \\
\hline 3 & Intrateam task disagreement & 4.11 & .57 & .02 & .11 & 1.00 & & & \\
\hline 4 & Decision-making comprehensiveness & 5.08 & .90 & $.39^{* *}$ & $.48^{* *}$ & -.13 & 1.00 & & \\
\hline 5 & Collaborative communication & 3.13 & .45 & $.21^{* *}$ & $.25^{* *}$ & $.17^{* *}$ & $.46^{* *}$ & 1.00 & \\
\hline 6 & Contentious communication & 2.06 & .62 & $-.16^{* *}$ & $-.32^{* *}$ & $-.16^{* *}$ & $-.28^{* *}$ & -.02 & 1.00 \\
\hline
\end{tabular}

4

\section{Analysis and results}

\subsection{Hypothesis testing}

This study performed two regression models: (1) decision-making comprehensiveness regressed on an intrateam task disagreement and the squared term of intrateam task disagreement, and (2) two project team performance variables regressed on three antecedent variables and their interaction terms. Multiple OLS regression models were used to test the hypothesis. First, the respondents' ratings for the relevant items of each construct were summed and divided by the number of items to obtain the multiple-item scales. Then a confirmatory factor analysis using varimax rotation was applied to verify the construct in this study. Finally, to reduce multicollinearity, all the variables were meancentered (replacing values by deviations from the means), as suggested by Aiken and West (1991). This procedure also had the effect of rendering the interaction terms more interpretable.

\subsection{The effect of intrateam task disagreement on decision-making comprehensiveness}

Table 2 reports the model explaining decisionmaking comprehensiveness, including the two phase regression results. In step 1, the model was run with intrateam task disagreement and its squared term. Then two team-specific controls, leader effectiveness and freedom to express doubts, were added to the equation in step 2. Based on Aiken and West's (1991:65-66) suggestion, an inverse U-shaped relationship is supported if the coefficient of the $\mathrm{X}$ term is positive and the coefficient of the square term $\left(\mathrm{X}^{2}\right)$ is negative. By taking steps 1 and 2 together, the regression results presented in Table 2 provide strong support for hypothesis $\mathrm{H} 1$, which predicts an inverse U-shaped relationship between intrateam task disagreement and decision-making comprehensiveness.

We further depicted the effect of intrateam task disagreement on decision-making comprehensiveness in Figure 2. Based on the empirical results of decision-making comprehensiveness regressed on intrateam task disagreement and its squared term, our data show a significantly negative quadratic coefficient of the intrateam task disagreement effect, indicating that there is a concave relationship between intrateam task disagreement and decision-making comprehensiveness. As shown in Figure 2, the optimal level of intrateam task disagreement was about 2 for our empirical data (represented by $\mathrm{X}^{*}$ ). The inverted U-shaped curve demonstrates that when the level of intrateam task disagreement 
is lower than the optimal level, increasing the level of intrateam task disagreement is positively related to a higher level of decisionmaking comprehensiveness. Yet, beyond a moderate level of intrateam task disagreement, the increase in the level of disagreement diminishes decision-making comprehensiveness.

Table 2

Results of the moderated regression analysis: decision-making comprehensiveness

\begin{tabular}{|c|c|c|c|c|}
\hline & \multicolumn{2}{|c|}{ Step 1} & \multicolumn{2}{|c|}{ Step 2} \\
\hline & b & t-Value & b & t-Value \\
\hline \multicolumn{5}{|c|}{ Main effect of intrateam task disagreement } \\
\hline Intrateam task disagreement $(\mathrm{H} 1)$ & 1.23 & $2.18^{m *}$ & .69 & $1.69^{*}$ \\
\hline Disagreement (squared term) & -.35 & $-2.35^{n *}$ & -.19 & $-1.88^{* *}$ \\
\hline \multicolumn{5}{|l|}{ Covariates } \\
\hline Leader effectiveness & & & .41 & $6.97^{\mathrm{x} *}$ \\
\hline Freedom to express doubts & & & .40 & $6.10^{m *}$ \\
\hline$R^{2}=$ & .04 & & .51 & \\
\hline Adjusted $R^{2}=$ & .04 & & .50 & \\
\hline$F=$ & $4.97^{x * *}$ & & $56.66^{\prime \prime}$ & \\
\hline
\end{tabular}

Figure 2

Effect of intrateam task disagreement on decision-making comprehensiveness

Decision-making

comprehensiveness

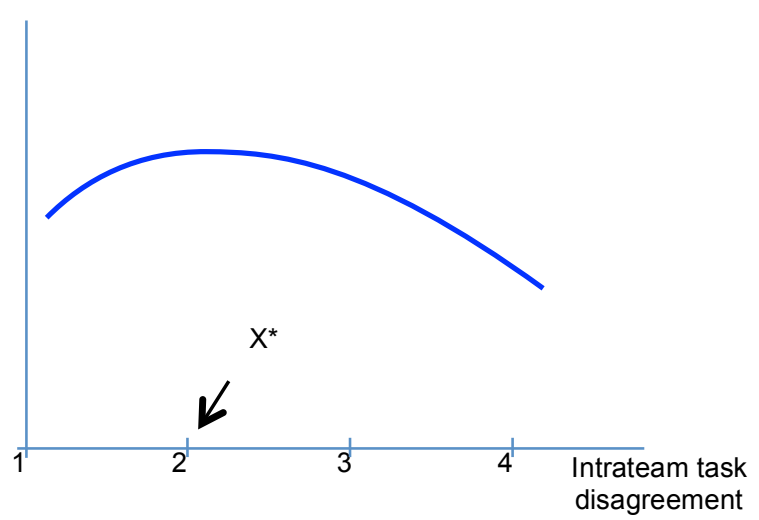

\subsection{Main and moderating effects of antecedents of project team performance}

The project team performance model first predicted relationships between three antecedent variables and two performance variables as shown in Table 3. Contradicting hypothesis $\mathrm{H} 2$, decision-making comprehensiveness seems to neither enhance innovativeness nor encourage constraint adherence. However, collaborative communication is negatively related to innovativeness, and has no effect on constraint adherence. H3 is not supported. Contentious communication has a significantly negative effect on constraint adherence as we expected, but it was not related to innovativeness. Thus, H4 is partially supported.

Collaborative communication was expected to strengthen the effect of decision-making comprehensiveness on project team performance (H5). The interaction effect on innovativeness was statistically significant, but was insignificant in constraint adherence. Thus H5 is partially supported. It was expected that contentious 
communication would mitigate the positive effect of decision-making comprehensiveness on project team performance (H6). Unexpectedly, the interaction between decision-making comprehensiveness and contentious communication on constraint adherence was significant, but the sign of the coefficient was positive. H6 is not supported.

Controls. Regarding team-specific controls, as shown in Table 2, leader effectiveness has a positive effect on decision-making comprehen- siveness. Additionally, the freedom to express doubts is positively related to decision-making comprehensiveness. As for organization-specific controls (see Table 3), while external environmental forces have no effect on innovativeness and constraint adherence, formalization has a significantly positive relationship with constraint adherence, while centralization has a significantly negative relationship with both project team performance variables.

Table 3

Results of moderated regression analysis: project team performance

\begin{tabular}{|c|c|c|c|c|c|c|}
\hline \multirow[b]{2}{*}{ Main and interaction effects } & & \multicolumn{2}{|c|}{ Innovativeness } & & \multicolumn{2}{|c|}{ Constraint adherence } \\
\hline & & b & t-Value & & b & t-Value \\
\hline \multicolumn{7}{|l|}{ Main effects of intrateam task disagreement } \\
\hline Decision-making comprehensiveness $(\mathrm{H} 2)$ & $(+)$ & -.48 & $-1.63^{*}$ & $(+)$ & .01 & .05 \\
\hline Collaborative communication (H3) & $(+)$ & -.80 & $-2.16^{\mathrm{x}}$ & $(+)$ & .14 & .43 \\
\hline Contentious communication $(\mathrm{H} 4)$ & $(-)$ & -.35 & -1.08 & $(-)$ & -.96 & $-3.36^{\cdots \cdots}$ \\
\hline \multicolumn{7}{|l|}{ Interaction effects } \\
\hline $\begin{array}{l}\text { Decision-making comprehensiveness } \times \text { collaborative } \\
\text { communication }(\mathrm{H} 5)\end{array}$ & $(+)$ & .15 & $2.11^{* *}$ & $(+)$ & -.02 & -.30 \\
\hline $\begin{array}{l}\text { Decision-making comprehensiveness } \times \text { contentious } \\
\text { communication }(\mathrm{H} 6)\end{array}$ & $(-)$ & .05 & 0.87 & $(-)$ & .14 & $2.50^{* * * *}$ \\
\hline \multicolumn{7}{|l|}{ Covariates } \\
\hline External environment forces & & .10 & 1.04 & & .14 & 1.61 \\
\hline Formalization & & .06 & .71 & & .33 & $4.28^{x \times x}$ \\
\hline Centralization & & -.25 & $-2.99^{m * *}$ & & -.35 & $1.90^{*}$ \\
\hline$R^{2}=$ & & .23 & & & .37 & \\
\hline Adjusted $R^{2}=$ & & .20 & & & .35 & \\
\hline$F=$ & & $8.02^{n * m}$ & & & $15.6^{m \times n}$ & \\
\hline
\end{tabular}

5

\section{Conclusions and discussions}

Overall, the empirical evidence supports some hypothesized relationships in the theoretical framework of this study. Specifically, there is a concave relationship between intrateam task disagreement and decision-making comprehensiveness. Rather, except that contentious communication adversely affects constraint adherence, the main effect of decision-making comprehensiveness, collaborative communication and contentious communication on project team performance is, incredibly, contrary to this study's expectations. However, decision-making comprehensiveness in collaborative communication teams was significantly and positively related to innovativeness, and the interaction between decisionmaking comprehensiveness and contentious communication has a significantly positive effect on constraint adherence.

In summary, this study reveals a complex scenario in terms of the internal dynamics of cross-functional teams that might contribute to the following aspects of NPD theory. First, the results show that there is a concave relationship between intrateam task disagreement and decision-making comprehensiveness, providing evidence to help resolve the debate between those who say that intrateam disagreement encourages decision-making comprehensiveness and those who suggest that conflicts may, in 
fact, be detrimental to it. That is, at a moderate level of intrateam task disagreement, the effectiveness of decision-making comprehensiveness will be highest.

Too little intrateam task disagreement is harmful to decision-making comprehensiveness, because it discourages the likelihood of the combination of different points of view and diverse information sources to create a new knowledge base in the decision-making process. Intrateam task disagreement is a measure of the diverse perceptual filters of people feeding information into the decision-making process. The combined perspectives of all the functions are necessary to mirror the complexity of the competitive environment. A low level of intrateam task disagreement provides a weak incentive for generating many alternative courses of action, thoroughly analyzing all strategic options, and using multiple criteria when making decisions. Thus, when the level of intrateam task disagreement is lower than the optimal level, increasing the level of intrateam task disagreement facilitates knowledge creation.

Equally important is the fact that too much intrateam task disagreement is inimical to decision-making comprehensiveness, because managing the functional interfaces within crossfunctional project teams can be costly. However, when handling bureaucratic costs caused by intrateam disagreement, it is often used to find teams resorting to simplifying heuristics or algorithmic problem-solving, which actually constrains the teams' ability to discover novel linkages from all new initiatives (Troy, Hirunyawipada \& Paswan, 2008). Thus, as the level of disagreement increases beyond the optimal level, increasing the level of intrateam task disagreement decreases decision-making comprehensiveness.

Second, contrary to our expectations, decision-making comprehensiveness does not affect innovativeness and constraint adherence. When it comes to innovativeness, one possible explanation is that, to achieve comprehensiveness, the decision-making process will require more current information that exists in their surroundings (i.e., channel members, customers and competitors). In other words, when teams focus on the operating environment, they monitor what currently exists in their immediate environments. However, creative ideas, by definition, must depart from what exists in the product category (Andrews \& Smith, 1996). Therefore, decision-making comprehensiveness does not appear to be the most fruitful source of creative ideas or innovativeness. This finding is also consistent with the conjecture that creative ideas for marketing established products seldom come from studying direct competitors (Park \& Smith, 1990). As to constraint adherence, because diverse input is not only necessary to achieving decision-making comprehensiveness but is also foundational to the development of new product knowledge, it is possible that achieving decision-making comprehensiveness can be costly and highly time-consuming when a team is confronting intensive industry competition and technological dynamism. Thus decision-making comprehensiveness adversely affects constraint adherence, which may be particularly true when there is time pressure.

Third, a surprise in the antecedents of project team performance is the role of collaborative communication. Despite its intuitive appeal, collaborative communication has a significantly negative effect on innovativeness. It is not clear why collaborative communications was significantly and negatively related to innovativeness, as one would have expected intuitively. Future research is needed to examine this. One of the possible explanations is that collaborative communication is more about finding solutions to problems, so the goals are geared towards problem-solving rather than the generation of ideas. This explanation is consistent with the conjecture that collaboration is a joint endeavor, in which multiple parties all bring their own, potentially unique perspectives on completing a task and in so doing overcome barriers and bridge differences (Mintzberg, Dougherty, Jorgensen \& Westley, 1996). Additionally, as Lovelace, Shapiro, and Weingart (2001:790) suggested if innovation is the primary concern, team members need to express their task disagreements in a collaborative manner. But there is likely to be the dilemma of a connection between task and motion. In other words, task disagreement affects the degree of harmonious crossfunctional relationships, thereby decreasing the likelihood of collaborative communication. Moreover, despite the fact that collaborative 
communication facilitates the integration of diverse skills (i.e., breadth), marketing literature emphasizes that a more substantial grounding in specific major deep business knowledge is also critical to creativity (Andrews \& Smith, 1996:184).

Fourth, extending the conclusions by Lovelace, Shapiro, and Weingart (2001), the empirical evidence seems to support that the lack of contentiousness within a project team was more significantly associated with its ability to adhere to budgets and schedules.

Finally, our results indicated that decisionmaking comprehensiveness diminishes (1) the adverse effect of collaborative communication on innovativeness and (2) the adverse effect of contentious communication on constraint adherence. A possible explanation is that, as the decision-making process is more comprehensive, it reduces the potential of the NPD project team falling victim to specific cognitive biases associated with incomplete information (Miller, 2008). This enables decision-makers to become more realistic and effective in their assessments of the environment (Sniezek, 1992), thereby reducing the necessity of conflict communications and the resulting adverse influences on project team performance.

\subsection{Limitations and future research directions}

This study has certain limitations. First, the cross-sectional nature of data collection does not facilitate testing of the causal sequences proposed in this study's framework. A longitudinal research design is necessary to validate these claims of causality.

Second, all of our data was self-reported, and does not differ from previous work. However, as for our data, the likelihood of a common method variance may not seriously affect the conclusions drawn from our study because the criterion variables (innovativeness and constraint adherence) and the other variables were obtained from two different kinds of informants, respectively. For this study, the team/ project leader provided information on two criterion variables, i.e., innovativeness and constraint adherence; whereas the second kind of respondents provided data on team atmosphere, organizational internal controls and the control variable.

Third, this study assessed team performance using only two subjective measures. However, this study does not have evidence to show that our perceptual measures of team performance are quality predictors of objective measures of performance. Thus, we recommend further research on whether the criterion variables can be assessed using a comprehensive measure that contains several subjective measures (such as both innovativeness and constraint adherence in this study) and objective financial performance measure (such as ROIC).

Endnotes:

1 Each sample contains two kinds of key informants.

2 If one half of the respondents scale on 1 and the other on 5, the maximum possible variation can be obtained as follows; $\sigma^{2}=\left[(7-4)^{2}+(1-4)^{2}\right] \times 1 / 2=9$

3 A desired sample size for this study was obtained, that is, $n=\left[(1.96)^{2} \cdot(9)\right] /(0.35)^{2}=283$

\section{References}

AIKEN, L.S. \& WEST, S.G. 1991. Multiple regression: testing and interpreting interactions. Newbury Park, CA: Sage Publications.

ANDREWS, J. \& SMITH, D.C. 1996. In Search of marketing imagination: factors affecting the creativity of marketing programs for mature products. Journal of Marketing Research, 33(May):174-187.

BOURGEOIS III, L.J. \& EISENHARDT, K.M. 1988. Strategic decision process in high velocity environments: four cases in the microcomputer industry. Management Science, 34(7):816-835.

BROWN, S.L. \& EISENHARDT, K.M. 1995. Product development: past research, present findings, and future directions. Academy of Management Review, 20(2):343-378. 
DE LUCA, L.M. \& ATUAHENE-GIMA, K. 2007. Market knowledge dimensions and cross-functional collaboration: examining the different routes to product innovation performance. Journal of Marketing, 71(January):95-112.

DILLMAN, D.A. 1978. Mail and telephone surveys: the total design method. New York: Wiley. DOUGHERTY, D. 1992. Interpretive barriers to successful product innovation in large firms. Organization Science, 3(2):179-202.

DYER, B \& SONG, XM. 1997. The impact of strategy on conflict: a cross-national comparative study of U.S. and Japanese firms. Journal of International Business Studies, 28(3):467-493.

FREDRICKSON, J.W. \& MITCHELL, T.R. 1984. Strategic decision processes: comprehensiveness and performance in an industry with an unstable environment. Academy of Management Journal, 27(2):399-423. GRIFFIN, A. \& HAUSER, J.R. 1996. Integrating R\&D and marketing: A review and analysis of the literature. Journal of Product Innovation Management, 13(May):191-215.

INNAMI, I. 1994. The quality of group decisions, group verbal behavior, and intervention. Organizational Behavior and Human Decision Processes, 60, 409-430.

LAWRENCE, P.R. \& LORSCH, J.W. 1967. Organization and Environment. Richard D. Irwin, Inc., Homewood, IL.

LOVELACE, K., SHAPIRO, D.L. \& WEINGART, L.R. 2001. Maximizing cross-functional new product teams' innovativeness and constraint adherence: a conflict communications perspective. Academy of Management Journal, 44(4):779-793.

LU, IUAN-YUAN \& CHANG, TSUN-JIN. 2002. A contingency model for studying R\&D-marketing in NPD context. International Journal of Technology Management, 24(2/3):143-164.

MASON, R.O. \& MITROFF. I.M. 1981. Challenging strategic planning assumptions. New York: John Wiley \& Sons.

MILLER, C.C. 2008. Decisional comprehensiveness and firm performance: towards a more complete understanding. Journal of Behavioral Decision Making, 21(5):598-620.

MILLER, C.C., BURKE, L.M. \& GLICK, W.H. 1998. Cognitive diversity among upper-echelon executives: implications for strategic decision processes. Strategic Management Journal, 19(1):39-58.

MINTZBERG, H., DOUGHERTY, D., JORGENSEN, J. \& WESTLEY, F. 1996. Some surprising things about collaboration-Knowing how people connect makes it work better. Organizational Dynamics, 25(4):60-71.

MITCHELL, R., NICHOLAS, S. \& BOYLE, B. 2009. The role of openness to cognitive diversity and group processes in knowledge creation, Small Group Research, 40(5):535-554.

NOHRIA, N. \& GULATI, R. 1996. Is slack good or bad for innovation? Academy of Management Journal, 39(5):1245-1264.

PARK, C.W. \& SMITH, D.C. 1990. Product class competitors as sources of innovative marketing strategies. Journal of Consumer Marketing, 7(Spring):27-38.

PHILLIPS, E. \& CHESTON, R. 1979. Conflict resolution: what works? California Management Review, 21:76-83

SETHI, R. 2000. Superordinate identity in cross-functional product development teams: its antecedents and effect on new product performance. Journal of Academy of Marketing Science, 28(Summer):330-344.

SETHI, RAJESH, SMITH, D.C. \& PARK, C.W. 2001. Cross-functional product development teams, creativity, and the innovativeness of new consumer products. Journal of Marketing Research, 38(February):73-85.

SIMONS, T., PELLED, L.H. \& SMITH, K.A. 1999. Making use of difference: diversity, debate, and decision comprehensiveness in top management teams. Academy of Management Journal, 42(6):662-673.

SLOTEGRAAF, R.J. \& ATUAHENE-GIMA, K. 2011. Product development team stability and new product advantage: the role of decision-making processes. Journal of Marketing, 75(January 2011):96-108.

SNIEZEK, J.A. 1992. Groups under uncertainty: an examination of confidence in group decision making. Organizational Behavior and Human Decision Processes, 52(1):124-155.

SONG, X.M., XIE, JINHONG \& DYER, B. 2000. Antecedents and consequences of marketing managers' conflict-handling behaviors. Journal of Marketing, 64(January):50-66. 
TROY, L.C., HIRUNYAWIPADA, T. \& PASWAN, A.K. 2008. Cross-functional integration and new product success: an empirical investigation of the findings. Journal of Marketing, 72(November):132-146. XIE, JINHONG., SONG, X.M. \& STRINGFELLOW, A. 1998. Interfunctional conflict, conflict resolution styles, and new product success: a four-cultural comparison. Management Science, 44(12,2/2): S192-S206.

VAN DE VEN, A.H. \& CHU, Y. 1989. A psychometric assessment of the Minnesota innovation survey, In A.H. Van de Ven, H.L. Angle, and M.S. Poole (eds.) Research on the management of innovation: The Minnesota studies:55-103, New York: Harper \& Row. 